\title{
http://bjas.journals.ekb.eg \\ The Impact of Serum Magnesium Level Disorders on Parathyroid Hormone and Alkaline Phosphatase Levels in Patients with Chronic Kidney Disease Stage 5 under Maintenance Hemodialysis
}

\author{
E.L.El-shehawy, S.B.Allah, A.T.Mahmoud,A.E.Mansour and O.M.Elsayed \\ Internal Medicine Dept., Faculty of Medicine, Benha Univ., Benha, Egypt \\ E-Mail Ola26@gmail.com
}

\begin{abstract}
Discrepancies between serum iPTH and BSAP levels, reflecting an uncoupling between bone resorption and formation, are uncommon but may be found in some patients. And only these discrepancies might be identified with variability in the estimations about BSAP Also iPTH. For instance, Delanaye et al. Demonstrated that there are huge discrepancies in the varieties for iPTH Furthermore BSAP focuses About whether over CKD-5D patients. [1] plasma magnesium focuses normally somewhat increment Likewise an outcome of decreased glomerular filtration. Serum first mass of the magnesium fixation need been demonstrated with be conversely connected with general What's more cardiovascular mortality, occurrence coronary heart disease, occurrence atrial fibrillation Also occurrence heart disappointment may be should ponder the impact of serum magnesium level issue once parathyroid hormone Furthermore basic phosphatase levels to tolerant with Ceaseless kidney sickness phase 5 under upkeep hemodialysis this investigation will be a observational cross sectional consider that might have been conveyed out in Benha college hospital, inward drug department, dialysis unit. Starting with january 2019 till june 2019. This examine included 120 patients phase $\mathrm{v}$ undergoing maintance hemodialysis. Oral Furthermore composed assent were made starting with each member when demonstrating the considered perfect those Investigation. Constantly on patients were clinically assessed Also needed schedule appraisal. Those mean agdistis of cases will be 50. 39+9. 64 with extent of (25-62) A long time Also percent about females might have been $54 \%$ Furthermore guys might have been $66 \%$. Intend systolic Circulatory strain $145 \pm 13.8$ for go of $70-130$, intend diastolic pulse 85 . $9 \pm 3$. 5 with reach about $60-80$, percent about hypertensive cases $25 \%$. 33. $3 \%$ of situations bring hypomagnesemia Furthermore 66. 7 needed typical first mass of the magnesium level. There will be sure helter skelter noteworthy relationship the middle of PHT Furthermore magnesium level Hypomagesemia altogether lift the level ofalkaline phosphatase Also parathromone hormaone levelin tolerant with Ceaseless kidney sickness phase 5 under support hemodialysis.
\end{abstract}

Keywords Magnesium, Alkaline phosphatase,parathormone hormone .

\section{Introduction}

Ceaseless kidney disease-mineral Also bone issue (CKD-MBD) is An systemic jumble described by persistency raised parathyroid hormone $(\mathrm{PTH})$, bone abnormalities, Extra-skeletal calcification Furthermore an expansive range about issue about mineral digestion system [2]. Renal bone illness shows for derangements for bone histologic discoveries for example, abnormalities Previously, bone turnover, mineralization, Also volume [3]. Bone histology may be the "gold standard" for conclusive analysis of the osteodystrophic lesion, Since it is An painful, exorbitant procedure, nephrologists depend mostly on soundness parathyroid hormone (iPTH) estimations should foresee bone histology Furthermore aide medicine. The 2009 kidney sickness moving forward worldwide conclusions (KDIGO) clinical act rules for bone digestion system Furthermore sickness On constant kidney sickness state that estimations of iPTH and bone-specific basic phosphatase (BSAP) might be used to assess bone infection [4]. In the past decades, studieson the disturbances about mineral What's more bone issue done CKD-MBDwere primarily centered on the unsettling about calcium/phosphate homeostasis [5]. However, up until recently, since various investigations have exhibited that first mass of the magnesium (Mg) assumed a paramount part in the pathophysiology of the cardiovascular framework What's more its issue were connected with an expanded danger from claiming cardiovascular horribleness Furthermore mortal sin [6]. The part Furthermore instrument about first mass of the magnesium homeostasis clinched alongside CKDMBD bring gained enormous sum about attention, various investigations need demonstrated that low serum magnesium levels were connected with vascular calcification and cardiovascular mortal sin to patients for end-stage renal infection [7]. Magnesium (Mg), the fourth mossycup oak abundant cation in the mankind's body, assumes a key part in various living techniques , past investigations in the all populace demonstrated that hypomagnesemia may be a danger to cardiovascular sicknesses (CVD), those sway of magnesium on the prognosis for patients once hemodialysis need been poorly investigated. The vitality of this mineral need been especially perceived because of its antiatherosclerotic impact [8]. To particular, a great deal consideration need been kept tabs around mineral Furthermore bone confusion (MBD) over ESRD as a conspicuous donor of the improvement for atherosclerosis What's more vascular calcification, to which phosphate maintenance will be recognized a magic part [9]. Various investigations bring indicated that low serum magnesium levels were connected with vascular calcification Also cardiovascular mortal sin Previously, patients for endstage renal illness. $\mathrm{Mg}$ supplementation need been turned out to restrain PTH secretion, same time 
hyperparathyroidism might have been recognized Concerning illustration a autonomous critical danger variable to cardiovasculardiseases [10].

\section{Patients and methods}

Moral thought endorsement might have been got by those medicinal establishment requisition What's more composed educated influenced man assent with a evidence concerning the idea of the examination need been made will any alternately know of the enlisted patients. This examine may be a cross sectional, observational ponder that might have been conveyed out in Benha school doctor's facilities inward drug department, dialysis unit. Starting with january 2019 till june 2019.

This examine incorporated 120 patients phase $\mathrm{v}$ undergoing maintance hemodialysis. Consideration criteria included; agdistis more than eighteen A long time patients stage $\mathrm{v}$ undergoing maintance hemodilaysis. Prohibition criteria included; critical infection,Malignancy history of parathyroidectomy (PTX), What's more flimsy therapeutic condition Throughout those past 30 times.

The sum included patients underwent point by point historical backdrop bringing with extraordinary thoughtfulness regarding period sexual orientation ,the effectiveness of hemodialysis might have been ascertained Toward surveying the urea decrease rate (URR) diabetes mellitus (type) hypertension What's more pill admission complex phosphate binders Also Proton pump inhibitors, Vitamin D, Calcimimetic.

They were clinically assessed by and large for sress looking into blood presure,cardiac , examination, and lab investigations were carried including including comp; ete blood picture ,cRP, serum creatinine ,Blood urea ,Serum egg whites, Serum basic phosphatase ,Serum calcium ,Serum phosphorus, product of calcium and phosphorus, Serum magnesiumand serum soundness PTH These blood tests will be measured at the begin of the hemodialysis session after an 8- with 12-h quick.

On the whole patients, the dialysis calendar might have been $4 \mathrm{~h}, 3$ times/week utilizing bicarbonate dialysate.

Blood specimens for determination for biochemical parameters were gathered When those starting of the dialysis session. Venous blood specimens were drawn from suitableness veins with detached fitting tourniquet. Then afterward centrifugation, blood might have been aliquoted done cryovials. Specimens for complete blood check were gathered done tubes holding EDTA K2 - 2H2O. Blood urea, serum creatinine, albumin, $\mathrm{Ca}$, phosphate, basic phosphatase, blood sugar, lipids, Also uric corrosive were measured utilizing standard research center strategies. Serum PTH test might have been performed utilizing electrochemiluminescence immunoassay on the fully robotized VIDAS (Biomerieux, Marcy l'Etoile, France). Those tests were centrifuged, et cetera those serum might have been solidified In $-40^{\circ}$ until appraisal.

An Pilot ponder might have been conveyed crazy ahead 12 patient $(10 \%$ from claiming investigation sample) on test feasibility, materialness Also clarity of routines.

\section{1 Factual dissection}

Dissection for information might have been carried out utilizing measurable project for social science rendition 20 (SPSSInc. , Chicago, IL, USA). Quantitative variables were depicted in the type of mean Furthermore standard deviation. Qualitative variables were portrayed Likewise amount What's more percent. So as will analyze parametric quantitative variables between two groups, learner $t$ test might have been performed. Qualitative variables were looked at utilizing chi-square (X2 ) test alternately Fisher's accurate test The point when frequencies were beneath five. Pearson relationship coefficients were used to evaluate the companionship the middle of two typically disseminated variables. When a variable might have been not typically distributed, An p quality $<0.05$ is viewed as noteworthy.

\section{Results}

Table (1) Demographic data of the studied cases.

\begin{tabular}{lll}
\hline Variable & & \\
\hline Age (years) & \multicolumn{3}{l}{} \\
Mean \pm SD & \multicolumn{2}{l}{$50.39 \pm 9.64$} \\
Range & $25-62$ & \\
& No. & $\%$ \\
Sex & & \\
Female & 54 & 45.8 \\
Male & 66 & 54.2 \\
\hline
\end{tabular}

This table shows that the mean age of cases is $50.39 \pm 9.64$ with range of (25-62) years and percent of females was $54 \%$ and males was $66 \%$.

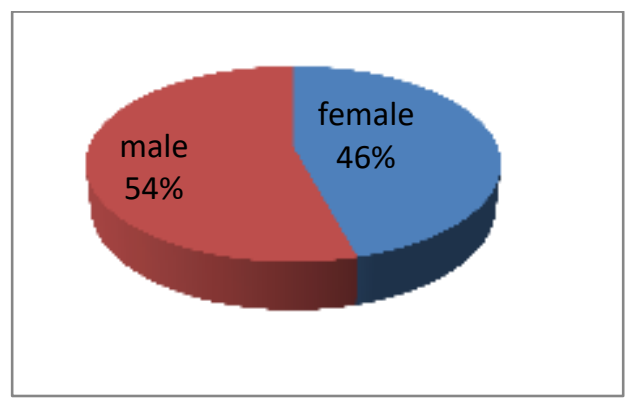

Fig (1) Sex of the studied cases. 
Table (2) Anthropometric measures of the studied cases.

\begin{tabular}{ll}
\hline Variable & \\
\hline Weight & \\
Mean \pm SD & $71.4 \pm 6.2$ \\
Range & $60-110$ \\
Height & \\
Mean \pm SD & $173.5 \pm 24.3$ \\
Range & $159-185$ \\
BMI & \\
Mean \pm SD & $23.5 \pm 1.6$ \\
Range & $19-35$ \\
\hline
\end{tabular}

This table shows that mean weight of the studied cases was $71.4 \pm 6.2 \mathrm{~kg}$ with range of $(60-110) \mathrm{kg}$, mean height of the studied cases was $173.5 \pm 24.3 \mathrm{~cm}$ with range of (159-185) $\mathrm{cm}$ and mean BMI of the studied cases was $23.5 \pm 1.6 \mathrm{~kg} / \mathrm{m}^{2}$ with range of (1935) $\mathrm{kg} / \mathrm{m}^{2}$.

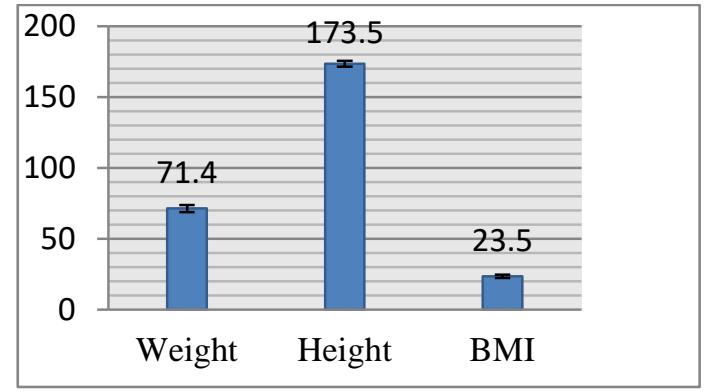

Fig (2)Mean values of anthropometric measures of studied cases .

Table (3) Cardiovascular characteristics of the studied cases .

\begin{tabular}{lcc}
\hline Variable & \\
\hline Systolic blood pressure & \\
Mean \pm SD & $145 \pm 13.8$ \\
Range & $70-130$ \\
Diastolic blood pressure & & \\
Mean \pm SD & $85 \pm 3.5$ & \\
Range & $60-80$ & \\
Hypertension & $\mathrm{N}$ & $\%$ \\
Yes & 30 & 25.0 \\
No & 90 & 75.0 \\
\hline
\end{tabular}

This table shows that mean systolic blood pressure $145 \pm 13.8$ with range of $70-130$, mean diastolic blood pressure $85.9 \pm 3.5$ with range of $60-80$, percent of hypertensive cases $25 \%$.

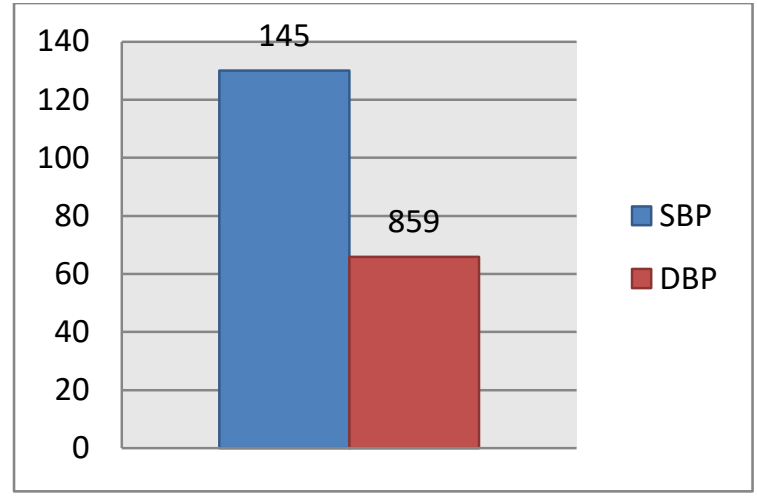

Fig (3) Mean value of systolic and diastolic blood pressure.

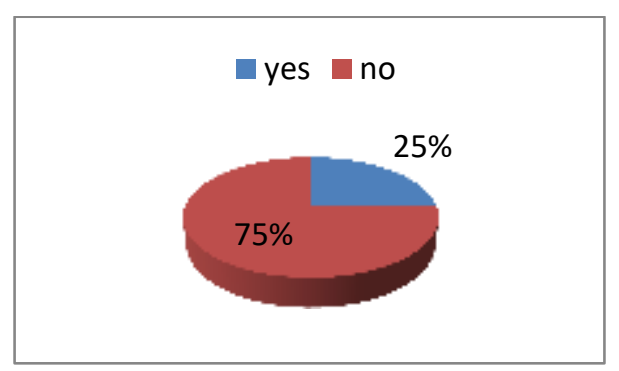

Fig (4) Hypertension of the studied case.

Table (4) Dialysis characteristics of of the studied cases .

\begin{tabular}{|c|c|c|}
\hline \multicolumn{3}{|l|}{ Variable } \\
\hline \multicolumn{3}{|c|}{ Session length per week (Hours) } \\
\hline Mean \pm SD & \multicolumn{2}{|c|}{$11.7 \pm 1.1$} \\
\hline Range & \multicolumn{2}{|c|}{$8-13$} \\
\hline Dialyzer type & $\mathrm{N}$ & $\%$ \\
\hline Low-flux & 52 & 43.3 \\
\hline High-flux & 68 & 56.7 \\
\hline \multicolumn{3}{|l|}{ Dialysis mode } \\
\hline Hemodialysis & 105 & 87.5 \\
\hline Hemodiafiltration & 15 & 12.5 \\
\hline
\end{tabular}

This table shows that mean Session length per week was $11.7 \pm 1.1$ with range of 8-13 hours, Lowflux was present in $56.7 \%$ and High-flux was in $43.3 \%$, heamodialysis in $87.5 \%$ and Hemodiafiltration in $12.5 \%$.

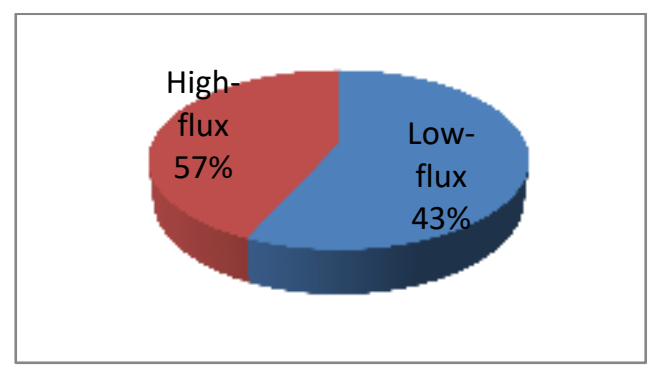

Fig (5) Dialyzer type of the studied groups. 


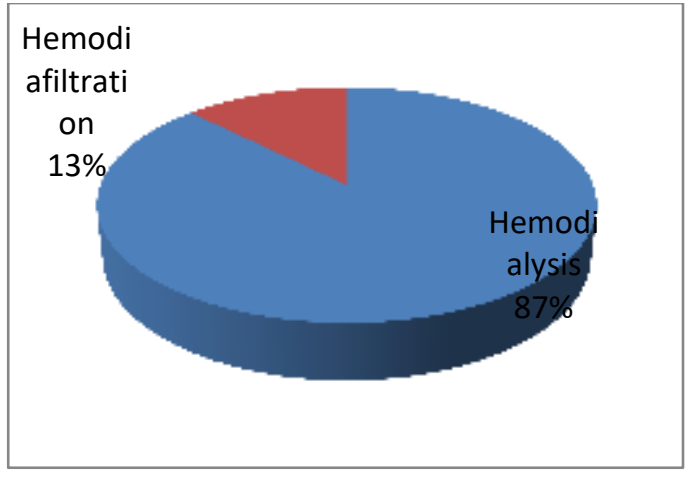

Fig (6) Dialysis mode of the studied groups.

Table (5) Diabetes Mellitus of the studies cases.

\begin{tabular}{lcc}
\hline Variable & \\
\hline DM duration & & \\
Mean \pm SD & $15 \pm 13.71$ & \\
Range & $10-20$ & $\%$ \\
Prevalence & $\mathrm{N}=120$ & 54.2 \\
Yes & 65 & 45.8 \\
No & 55 & \\
Type & $\mathrm{N}=65$ & 18.1 \\
Type 1 & 10 & 81.8 \\
Type2 & 55 & \\
\hline
\end{tabular}

This table shows that $15 \pm 13.71$, mean DM duration was $15 \pm 13.71$, of 65 cases $18.1 \%$ had type 1 and $81.8 \%$ had type 2 .

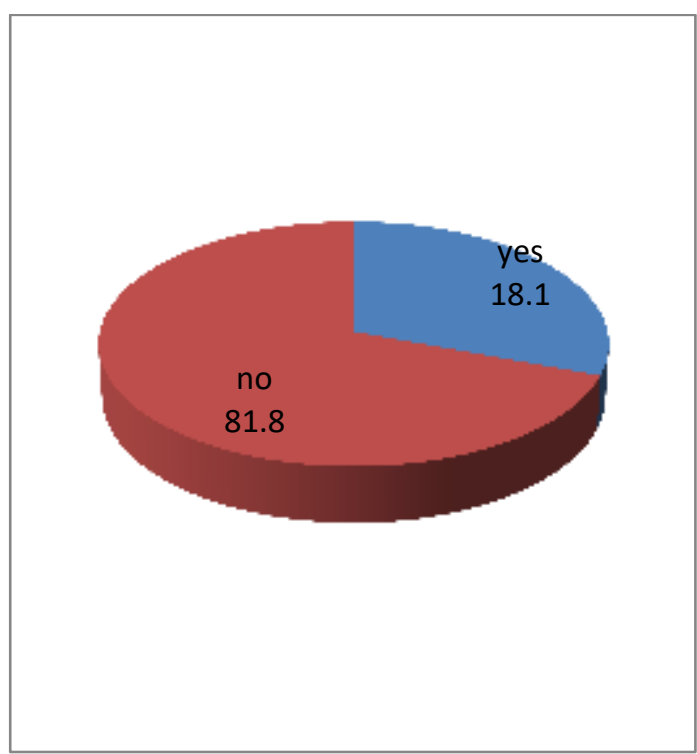

Fig (7) Prevalence of DM.
Table (6) Laboratory data of the studied cases.

\begin{tabular}{lc}
\hline Variable & \\
\hline Haemoglobin & \\
Mean \pm SD & $8.48 \pm 2.08$ \\
Range & $5.5-11$ \\
CRP & \\
Mean \pm SD & $0.55 \pm 0.49$ \\
Range & $0-1$ \\
INR & \\
Mean \pm SD & $1.2 \pm 0.33$ \\
Range & $0.8-2.3$ \\
Albumin & \\
Mean \pm SD & $4.08 \pm 0.28$ \\
Range & $(3.5-4.5)$ \\
\hline
\end{tabular}

This table shows that mean hemeglobin level $8.48 \pm 2.08 \mathrm{~g} / \mathrm{dl}$ with range of $(5.5-11) \mathrm{g} / \mathrm{dl} * 10^{3}$ with range of $(3.4-11)^{*} 10^{3}$, mean CRP was $0.55 \pm 0.49$ with range of $(0-1)$ and mean INR was $1.2 \pm 0.33$ with range of(0.8-2.3). Mean albumin level was $4.08 \pm 0.28$ with range of $(3.5-4.5)$

Table (7) Distribution of the studied cases according to magnesium status .

\begin{tabular}{lcc}
\hline Variable & & \\
\hline & $\mathbf{9 + 6}$ & $\mathbf{\%}$ \\
Magnesium status & & 33.3 \\
Hypomagnesemi & 40 & 66.7 \\
a & 80 & \\
$\begin{array}{l}\text { Normomagnese } \\
\text { mia }\end{array}$ & & \\
\hline
\end{tabular}

This table shows that $33.4 \%$ of cases have hypomagnesemia.

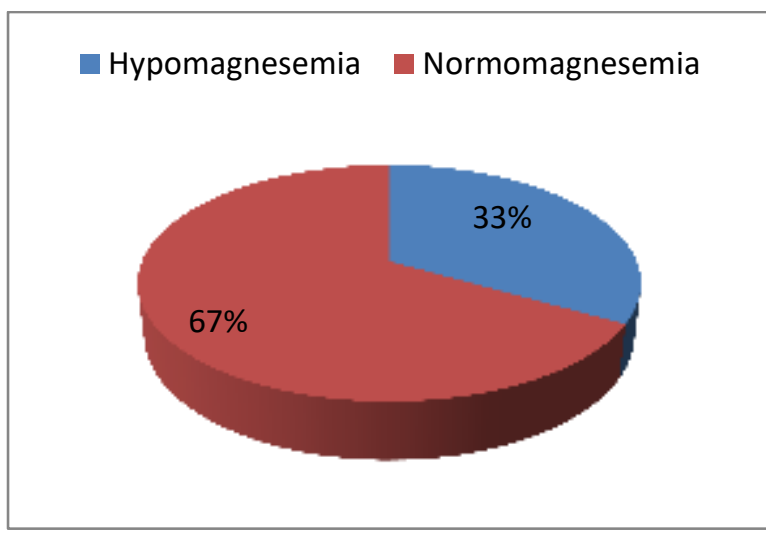

Fig (8) Distribution of the studied cases according to magnesium status. 
Table (9) Relation between Alkalin phosphatase, Parathyroid hormone ,calcium,phosphorous and hypomagnesemia of the studied cases.

\begin{tabular}{lcccc}
\hline Variable & $\begin{array}{c}\text { Hypomagesemia } \\
\mathbf{N = 4 0}\end{array}$ & $\begin{array}{c}\text { Normomagesemia } \\
\mathbf{N = 8 0}\end{array}$ & T test & P value \\
\hline $\begin{array}{l}\text { Magnesium } \\
\text { Mean } \pm \text { SD }\end{array}$ & $1.4 \pm 0.2$ & $2.2 \pm 0.2$ & 12.9 & $<$ \\
$\begin{array}{l}\text { Range } \\
\text { Alkaline phosphatase }\end{array}$ & $(1.7-2.2)$ & & $(\mathbf{H S})$ \\
$\begin{array}{l}\text { Mean } \pm \text { SD } \\
\text { Range }\end{array}$ & $236.2 \pm 80.5$ & $266.2 \pm 75.5$ & 2.007 & $\mathbf{0 . 0 4 7}$ \\
PTH & $210-1850$ & $210-1850$ & & $(\mathbf{S})$ \\
$\begin{array}{l}\text { Mean } \pm \text { SD } \\
\text { Range }\end{array}$ & $320.1 \pm 61.2$ & $360.1 \pm 60.2$ & 3.41 & $<\mathbf{0 . 0 0 1}$ \\
$\begin{array}{l}\text { Phosphous } \\
\text { Mean } \pm \text { SD }\end{array}$ & $100-420$ & $205-420$ & & $(\mathbf{H S})$ \\
Range & $5.2 \pm 1.2$ & $5.3 \pm 1.1$ & 0.455 & 0.649 \\
Calcium & $3.2-6.5$ & $3.2-6.5$ & & \\
Mean \pm SD & $9.3 \pm 0.38$ & $9.2 \pm 0.53$ & 1.06 & 0.289 \\
Range & $7.9-10.0$ & $7.9-10.0$ & & \\
\hline
\end{tabular}

This table shows that the mean Magnesium level in hypomagnesemia group is $1.7 \pm 0.2$ with range of (1-2.0) and mean Magnesium level in normomagnesemia group is $2.2 \pm 0.2$ with range of (12.5) with high significant difference between the two groups, high significant difference between the two

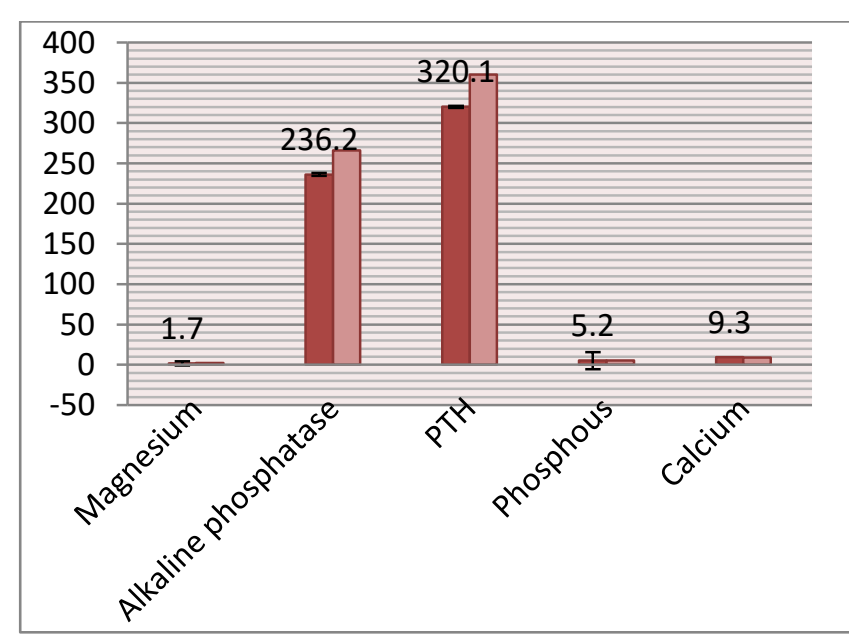

Fig (10) Mean Alkalin phosphatase, Parathyroid hormone of the studied groups.

Table (13) Correlation between Parathyroid hormone and magnesium level and alkaline phosphatase

\begin{tabular}{lll}
\hline Variable & \multicolumn{1}{c}{ PTH } \\
\hline alkaline phosphatase & R & P \\
& -0.711 & $<0.001$ \\
& & $(\mathrm{HS})$ \\
\hline
\end{tabular}

$r$ is for pearson's correlation co-efficent

This table shows that there is positive high significant correlation between PHT and magnesium level. groups as regard PTH, there is high significant difference between the two studied groups as regard Alkaline phosphatase, While there is no significant difference between the two groups as regard Phosphous or Calcium .

\section{Discussion}

Parathyroid hormone (PTH) is a vital parameter in the pathogenesis about bone sickness over dialysis patients. The homeostasis for phosphorus, calcium, Also first mass of the magnesium $(\mathrm{Mg})$ will be bended clinched alongside constant renal disappointment [11] mg will be generally excreted Toward kidney. The homeostasis of $\mathrm{mg}$ will be annoyed to unending kidney sickness. To fact, kidney need an essential part in the homeostasis $\mathrm{mg}$. Those regulation about $\mathrm{mg}$ digestion system may be impacted by filtration What's more reabsorption [12]. Hyperphosphatemia, hypermagnesemia Also hypocalcemia are perceivable On propelled constant kidney sickness. Disturbances On mg digestion system over constant renal disappointment might mostly help those improvement of unending kidney disease-mineral bone issue (Wolf, 2012). It need been gathered that plasma mg need An vital part with control those emission of PTH. Plasma mg may be skilled of modulating emission for PTH. Late investigations uncovered low serum mg levels in patients with kidney sickness bring been connected will expanded mortal sin. It need been distinguished that that easier plasma mg qualities are identified with calcification from claiming cardiovascular tissue and vespula vulgaris dividers which will increment mortal sin and horribleness clinched alongside hemodialysis patients [13]. Our study meant on ponder those impact for serum first mass of the magnesium level issue for parathyroid hormone What's more basic phosphatase levels Previously, tolerant with Ceaseless kidney sickness stage 5 under support hemodialysis. 
Our examine included 120 stage 5 hemodialysis patients about whom 40 were introduced for hypomagnesemia, those introduced populace intend

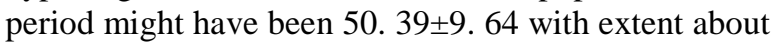
(25-62) A long time Furthermore percent of females might have been $54 \%$ Also guys might have been $66 \%$.

[11] conducted their consider on 56 hemodialysis patients for hemodialysis focus of Hajar clinic for Shahrekord to 2015, discovered that $61.5 \%$ from claiming 52 patients were male. Intend \pm sd about patients' agdistis might have been $60.5 \pm 17.7$ A long time for average about 63 quite some time of age (minimum age; 13 quite some time old, greatest age; 52 A long time old). And [14] who led An crosssectional examine performed in the HD area of the Hajar therapeutic instructive Furthermore restorative focal point of Shahrekord school of medicinal Sciences clinched alongside Shahrekord, Iranthey directed their consider through what added up to 41 patients (males $=26$, females $=15$ ), the intend \pm sd period of the investigation patients might have been 46 $( \pm 17.6)$ quite some time.

In the current examine those imply session length for every week might have been $11.7 \pm 1$. 1 with extend of 8-13 hours, Low-flux might have been display Previously, 56. 7\% and High-flux might have been done 43. 3\%, heamodialysis for 87 . $5 \%$ Furthermore Hemodiafiltration clinched alongside 12 . $5 \%$.

This might have been clinched alongside concordant [11] who recognized that those Normal span from claiming dialysis might have been $44 \pm 39$. 5 months (median 36 months). Moreover the dialysis measurement might have been $517 \pm 479$ weeks (median; 414 weeks).

Our consider checked that imply dm span might have been 18. $63 \pm 13.71$, about 65 cases $49.2 \%$ needed kind 1 What's more $45.8 \%$ needed sort 2 .

This might have been clinched alongside concordant for [14]who recognized that there were 29 non-diabetic $(\mathrm{M}=18, \mathrm{~F}=11)$ Also 12 diabetic patients.

On our examine we discovered that imply hemeglobin level might have been $8.48 \pm 2.08 \mathrm{~g} / \mathrm{dl}$ with extent about (5. 5-11)g/dl, imply platelets might have been $(179 \pm 64) * 103$ for go from claiming (80-

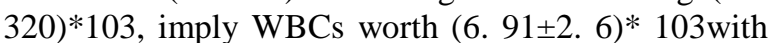
range of $(3.4-11)^{*} 103$, mean crp might have been 0 . $55 \pm 0$. 49 with reach for (0-1) Also intend inr might have been $1.2 \pm 0.33$ for range of(0.8-2.3). Intend egg whites level might have been $4.08 \pm 0.28$ for go from claiming (3. 5-4. 5).

Our investigation exhibited that there is helter skelter critical connection between hypomagnesemia What's more creatinine level, likewise there is critical connection between hypomagnesemia What's more GFR Furthermore urea.

On our study the intend magnesium level clinched alongside hypomagnesemia bunch may be 1 . $7 \pm 0.2$ with extent of (1-2.0) Also mean magnesium level over normomagnesemia aggregation may be 2.2 \pm 0.2 for reach for (1-2. 5) for helter skelter critical distinction the middle of the two groups, secondary huge distinction between those two gatherings Concerning illustration respect PTH, there is secondary critical distinction the middle of those two mulled over bunches as respect basic phosphatase, same time there is no noteworthy distinction the middle of the two gatherings Similarly as see Phosphous alternately calcium.

This might have been inconcordant with[11]found An altogether sure relationship for iPTH with serum mg levels.

This might have been Previously, concordant for [10] conducted An investigation ahead 1231 patients to nine japanese focuses who needed off hemodialysis for end-stage renal infection. They discovered serum mg levels were essentially lifted to patients with low iPTH.

This might have been in concordant with [15] reported that intend $\mathrm{mg}$ worth might have been 1 . $26 \pm 0.37 \mathrm{mEq} / \mathrm{L}$ over low basic phosphatase action gathering Furthermore 1. $8 \pm 0.56 \mathrm{mEq} / \mathrm{L}$ clinched alongside controls which might have been also statistically significant, also they showed that a huge certain connection between mg What's more high mountain which proposes those way that divalent metal particle mg may be a powerful stimulator for high mountain.

نكتب [16] illustrated On their contemplate that mg What's more $\mathrm{Zn}$ ions cooperate to initiate those non particular tissue basic phosphatase. On An investigation with respect to $110 \mathrm{HD}$ patients not accepting vitamin D, [17]demonstrated that serum $\mathrm{mg}$ levels were conversely associated for PTH levels Also that PTH levels were impacted Toward mg levels. Navarro closed that patients with deficiently low PTH levels demonstrated higher serum $\mathrm{mg}$ concentrations, suggesting that incessant hypermagnesemia may diminishing PTH emission or union.

This might have been On concordant with[18] led An investigation of 126 patients will focus those pathogenesis from claiming relative hypoparathyroidism $(\mathrm{PTH}<200 \mathrm{pg} / \mathrm{mL})$ Previously, HD patients, [18] showed that time-dependent PTH levels were conversely associated with serum $\mathrm{mg}$ levels. This might have been over concordant with. [19] concentrated on 20 patients for standard HD help will evaluate the impact of $\mathrm{mg}$ looking into circle plasma iPTH levels. Plasma levels about iPTH and 25$\mathrm{OH}$ Vit d were measured previously, then 10 weeks following the $\mathrm{mg}$ focus in the dialysate might have been expanded starting with 0.75 will $1.50 \mathrm{mmol} / \mathrm{L}$. They demonstrated An $36 \%$ climb in the mean predialysis plasma mg centralization Furthermore a $23 \%$ fall in the imply plasma iPTH fixation. Also, those intend plasma focuses from claiming $25-\mathrm{OH}$ Vit $\mathrm{d}$ levels decreased, in spite of the fact that this might have been not critical. Those creators finished up that 
a climb clinched alongside plasma mg focus lessens the circle plasma iPTH levels On normo-calcemic, uremic patients with at first both typical Also raised plasma PTH levels. On the disaffirm Previously, An cross-sectional ponder once 41 hemodialysis patients, [14] distinguished a opposite correspondence albeit insignificant, between serum mg quality and levels for iPTH. Likewise they discovered there might have been no critical relationship between serum mg levels What's more such variables including span about duration of the time once HD, serum ALP, plasma $\mathrm{HCO} 3$, serum $\mathrm{Ca}$, Furthermore $\mathrm{p}$ in the consider patients.

This might have been not Previously, concordant for [20]studied 22 uremic patients on incessant HD, utilizing diverse focuses about $\mathrm{mg}$ in the dialysate. After An six-month period, they didn't Figure whatever critical progressions in the serum PTH levels, they inferred that reasoned that the serum mg levels don't appreciably impact PTH emission over uremic patients for standard HD.

In the ponder from claiming [21] serum mg levels might have been $1.00+0.14 \mathrm{mg} / \mathrm{dL}$. They likewise discovered a feeble What's more opposite association the middle of $\mathrm{mg}$ serum level Also iPTH, which might have been not statistically noteworthy. They watched a opposite noteworthy relationship of $\mathrm{mg}$ What's more PTH levels to patients for serum PTH of over $300 \mathrm{pg} /$ $\mathrm{ml}$. However, done patients with serum PTH levels short of what $300 \mathrm{pg} / \mathrm{mL}$, no correspondence of serum $\mathrm{mg}$ for PTH might have been distinguished.

This might have been not concordant for [22] who distinguished a opposite connection from claiming serum $\mathrm{mg}$ for PTH levels. The ponder led around 110 hemodialysis people for imply agdistis for $55 \pm 14$ quite some time and the span of dialysis might have been $35 \pm 28$ months.

Additionally we discovered that there might have been An negative huge correspondence between first mass of the magnesium level What's more creatinie and urea, Additionally there might have been sure noteworthy relationship between magnesium level Also GFR.

We recognized in this contemplate that there might have been a sure noteworthy connection the middle of basic phosphatase level Also creatinine Furthermore urea, also there will be negative critical correspondence between basic phosphatase What's more GFR.

This might have been over concordant with [23] observed sure noteworthy correspondence the middle of PTHand high mountain Furthermore blood urea and negative significantcorrelation the middle of serum ca What's more blood urea. Yet extent from claiming hemodialysis patients is generally little. We propose bigger multicentric investigations with respect to this part of hemodialysis people.

All in all hypomagesemia essentially influence basic phosphatase What's more parathromone hormaone level.

\section{Conclusion}

Hypomagesemia significantly elevate the level ofalkaline phosphatase and parathromone hormaone levelin patient with chronic kidney disease stage 5 under maintenance hemodialysis

\section{References}

[1] A. O.Oweis, S. A.Alshelleh, A. K. Daoud, M. M. Smadi, \& K. H. Alzoubi, (). Inflammatory milieu in contrast-induced nephropathy a prospective single-center study. International journal of nephrology and renovascular disease;vol.11,pp.211-219, 2018.

[2] M.Cozzolino, P.Urena-Torres, M.G.Vervloet, Is chronic kidney disease-mineral bone disorder $+r$ (CKD-MBD) really a syndrome? Nephrol Dial Transplant;vol.29,pp.1815-1820, 2014

[3] S. M.Moe, \& T. L. Nickolas, Fractures in patients with CKD time for action;vol.25,pp.69-73,2016.

[4] Kidney Disease Improving Global Outcomes (KDIGO) CKD-MBD Work Group (2009). KDIGO clinical practice guideline for the diagnosis, evaluation, prevention, and treatment of chronic kidney disease-mineral and bone disorder (CKD-MBD). Kidney Int Suppl S1S130.

[5] RC.Shroff, R.McNair, J.N.Skepper, Chronic mineral dysregulation promotes vascular smooth muscle cell adaptation and extracellular matrix calcification. J Am Soc Nephrol;vol.21,pp.103112,2010 .

[6] D.Kolte, K.Vijayaraghavan, S.Khera,Role of magnesium in cardiovascular diseases. Cardiol Rev;vol.22,pp.182-192, 2014.

[7] M.Kanbay, M.I.Yilmaz, M.Apetrii,) Relationship between serum magnesium levels and cardiovascular events in chronic kidney disease patients. Am J Nephrol;vol.36,pp.228-237, 2012.

[8] S.Van Laecke, W.Van Biesen, R.Vanholder ,Hypomagnesaemia, the kidney and the vessels. Nephrol Dial Transplant; 27 4003-4010, 2012.

[9] F.Tentori, M.J.Blayney, J.M.Albert ()Mortality risk for dialysis patients with different levels of serum calcium, phosphorus, and PTH the Dialysis Outcomes and Practice Patterns Study (DOPPS). Am J Kidney Dis;vol. 52,pp.519-530, 2008.

[10] M. Ohya, S.Negi, , T.Sakaguchi, F. Koiwa, R.Ando, Y.Komatsu, , \& M.Ikeda, (). Significance of serum magnesium as an independent correlative factor on the parathyroid hormone level in uremic patients. The Journal of Clinical Endocrinology \& Metabolism;vol.99(10),pp. 3873-3878, 2014.

[11] M.Fooladgar, A.Malekpour Tehrani, S.AsgariSavadjani, \& S.Mardani, (). Serum magnesium in association with parathyroid hormone levels in routine hemodialysis patients. J.Parathyroid Disease;vol.6(1),pp.26-29, 2017. 
[12] A.Jovanovich, \& M.Chonchol, Phosphorus and Kidney Disease Mechanisms for Perturbed Phosphorus Homeostasis in Chronic Kidney Disease. In Clinical Aspects of Natural and Added Phosphorus in Foods. Springer, New York, NY;vol.36, pp. 187-199,2017.

[13] S.Melmed, , K. S. Polonsky, P. R. Larsen, \& H. M.Kronenberg, Williams textbook of endocrinology. Elsevier Health Sciences;vol.16, pp. 162-169,2015.

[14] A.Baradaran, \& H.Nasri, Correlation of serum magnesium with serum parathormone levels in patients on regular hemodialysis. Saudi journal of kidney diseases and transplantation;vol.17(3),pp.344, 2006.

[15] C. S. Ray, B.Singh, I.Jena, S.Behera, \& S.Ray, (). Low Alkaline Phosphatase (ALP) in adult population an indicator of Zinc (Zn) and Magnesium (Mg) deficiency. Current Research in Nutrition and Food Science J.l;vol.5(3),pp. 347352, 2017.

[16]F. J. Olorunniji, A.Igunnu, , J. O. Adebayo, R. O. Arise, \& S. O. Malomo, (2007). Cofactor interactions in the activation of tissue non-specific alkaline phosphatase Synergistic effects of $\mathrm{Zn} 2+$ and $\mathrm{Mg} 2+$ ions. Biokemistri; vol.25,pp. 19(2), r .. v.

[17] J. F. Navarro, C. Mora, \& J.Garcia, Serum magnesium and parathyroid hormone levels in dialysis patients. Kidney international;vol.57(6),pp. 2654, 2000.
[18] J. Y. Guh, H. C. Chen, H. Y. Chuang, S. C. Huang, L. C. Chien, \& Y. H. Lai, Risk factors and risk for mortality of mild hypoparathyroidism in hemodialysis patients. American journal of kidney diseases;vol. 39(6),pp. 1245-1254, 2002.

[19] R. S. MCGONIGLE, M. J. Weston, J. Keenan, D. B. Jackson, \& V.Parsons, (1). Effect of hypermagnesemia on circulating plasma parathyroid hormone in patients on regular hemodialysis therapy. Magnesium;vol.3(1),pp. 17, 1984.

[20] M.Gonella,F.Bonaguidi, G.Buzzigoli, V.Bartolini, \& G.Mariani, On the effect of magnesium on the PTH secretion in uremic patients on maintenance hemodialysis. Nephron;vol. 27(1),pp. 40-42, 1981

[21] A. A. Zeraati, M. Naghibi, A. Aminian, F. Sharifipour, R. Hekmat, \& M. S. BELADI, (). Correlation between serum magnesium and serum pth levels in patients with peritoneal dialysis; vol. 24(1), 127-129, 2011.

[22] P. S. Misra, A. Alam, M. L. Lipman, \& S. J. Nessim, (). The relationship between proton pump inhibitor use and serum magnesium concentration among hemodialysis patients a cross-sectional study. BMC nephrology;vol.16(1),pp. 136, 2015.

[23]H. A. Ahmed, K. M. Elzorkany, Y. S. Yasein, \& A. F. A. E. Saif, Prevalence of mineral bone disorders among hemodialysis patients in Menoufia Governorate, Egypt. Menoufia Medical $J . ; \operatorname{vol.30(3),pp.~687,2017.~}$ 